\title{
PENGARUH DISIPLIN KERJA DAN KOMPETENSI TERHADAP KINERJA PEGAWAI \\ (Studi kasus Pada Pusat Penelitian Kebijakan Pendidikan dan Kebudayaan \\ Kementerian Pendidikan dan Kebudayaan)
}

\author{
Hemmy Fauzan \\ Annisa Nur Hikmah \\ Fakultas Ekonomi dan Bisnis UIN Syarif Hidayatullah Jakarta \\ Email :hemmy.fauzan@uinjkt.ac.id
}

\begin{abstract}
The purpose of this research was to find out the influence of work discipline and competence partially and simultaneously on employee performance. This research using quantitative research methods with techniques od data collecting through spreading of questioner and supported secondary data. Data analysis method used is multiple linear regression analysis. With resoult of data processing data using SPSS 24. The sample in this research is a proportionate stratified random sampling. The number of samples is 86 respondents from employees of Pusat Penelitian Kebijakan Pendidikan and Kebudayaan (Puslitjakdikbud). The resultsof this research show that the variables of work discipline and competence partially and simultaneously have a significant influence on the performance of employees of Pusat Penelitian Kebijakan Pendidikan and Kebudayaan (Puslitjakdikbud). Employee performance variables can be explained by the variables work discipline and competence by $61,2 \%$. While the remaining at $33,8 \%$ is explained by other variables not included in this research.
\end{abstract}

Keywords: Work discipline, competence, and employee performance.

Abstrak: Tujuan dari penelitian ini adalah untuk mengetahui pengaruh disiplin kerja dan kompetensi secara parsial dan simultan terhadap kinerja karyawan. Penelitian ini menggunakan metode penelitian kuantitatif dengan teknik pengumpulan data melalui penyebaran kuesioner dan data sekunder yang didukung. Metode analisis data yang digunakan adalah analisis regresi linier berganda. Dengan pengambilan ulang data pengolahan data menggunakan SPSS 24. Sampel dalam penelitian ini adalah stratified random sampling proporsional. Jumlah sampel adalah 86 responden dari karyawan Pusat Penelitian Kebijakan Pendidikan dan Kebudayaan (Puslitjakdikbud). Hasil penelitian ini menunjukkan bahwa variabel disiplin kerja dan kompetensi secara parsial dan simultan berpengaruh signifikan terhadap kinerja karyawan Pusat Penelitian Kebijakan Pendidikan dan Kebudayaan (Puslitjakdikbud). Variabel kinerja karyawan dapat dijelaskan oleh variabel disiplin kerja dan kompetensi sebesar $61,2 \%$. Sedangkan sisanya sebesar 33,8\% dijelaskan oleh variabel lain yang tidak termasuk dalam penelitian ini.

Kata kunci: Disiplin kerja, kompetensi, dan kinerja karyawan. 


\section{Pendahuluan}

Kemajuan ilmu pengetahuan dan teknologi menuntut Pegawai Negeri Sipil (PNS) untuk menjalankan tugas pokok dan fungsinya dengan baik dan benar dalam memberikan pelayanan kepada masyarakat dan mencapai tujuan organisasi pemerintah. Pegawai Negeri Sipil (PNS) berkedudukan sebagai unsur aparatur Negara yang bertugas untuk memberikan pelayanan kepada masyarakat secara profesional, jujur, adil, dan merata dalam penyelenggaran tugas negara, pemerintah, dan pembangunan kepada masyarakat dengan dilandasi kesestiaan dan ketaatan kepada undang-undang 1945 dan pancasila.

Kedisiplinan sebagai fungsi operatif manajemen sumber daya manusia yang terpenting karena semakin baik disiplin pegawai semakin tinggi kinerja pegawai yang dapat dicapai. Pada saat ini masih banyak pegawai yang kurang memiliki disiplin kerja yang tinggi. Hal ini dapat dilihat dari adanya kemangkiran, adanya pegawai yang tidak masuk tanpa keterangan, terlambat datang ke kantor dan sering menambah waktu liburan misalnya disaat lebaran, hal ini juga dapat menjadi masalah dalam disiplin kerja (Putra. 2013). Jika dibiarkan akan melemahkan kehidupan bangsa dan negara. Lemahnya sistem pengawasan jam kerja di lingkungan PNS, setelah libur panjang pegawai masih terlihat ada yang berkeliran pada saat jam kerja dan mencuri waktu untuk melakukan kegiatan di luar pekerjaan, kemungkinan juga dapat menjadi penyebab masalah dalam disiplin kerja (Wildan Lutfi A dan Mayahayati K. 2015).

Penelitian ini dilakukan di Pusat Penelitian Kebijakan Pendidikan dan Kebudayaan merupakan bagian dari Badan Penelitian dan Pengembangan di bawah naungan Kementerian Pendidikan dan Kebudayaan. Dalam meningkatkan kedisiplinan pegawai Puslitjakdikbud mempunyai peraturan jam kerja pegawai yaitu Pada hari Senin- Kamis masuk pada pukul 07.30 WIB, waktu istirahat pada pukul 12.00-13.00 WIB dan pulang pada pukul 16.00 WIB sedangkan pada hari Jumat masuk pada pukul 07.30 WIB, waktu istirahat pada pukul 11.30-13.00 WIB dan pulang pada pukul 16.30 WIB. Puslitjakdikbud sebagai unit kerja yang bergerak di bidang penelitian ini, membutuhkan sumber daya manusia yang berkualitas serta mendukung dalam meningkatkan kinerja, Menurut data yang ada dalam kinerja puslitjakdikbud jumlah antara target dan realisasi dari beberapa indikator kinerja belum maksimal. Terlihat bahwa masih terdapat pegawai dengan tanggung jawab yang dibebankan belum berjalan dengan baik. Seharusnya, hal seperti ini bisa dimaksimalkan, jika dalam pelaksanaannya manajemen waktu dan sumber daya manusianya dapat di maintance dengan baik, agar pencapaian dari target kerja dapat tercapai. Dengan demikian, setelah memperhatikan masalah-masalah di atas maka peneliti tertarik untuk melakukan penelitian dengan judul "Pengaruh disiplin kerja dan kompetensi terhadap kinerja pegawai (Studi Kasus Pada Pusat Penelitian Kebijakan Pendidikan dan kebudayaan".

\section{Landasan Teori}

\subsection{Manajemen}

Menurut Stoner (1982:8) dalam (Handoko, 2008:2) manajemen merupakan proses perencanaan, pengorganisasian, pengarahan dan pengawasan usaha-usaha para anggota organisasi dan penggunaan sumber daya organisasi lainnya agar mencapai tujuan organisasi yang telah ditetapkan. Manajemen adalah ilmu dan seni yang mengatur proses pemanfaatan sumber daya manusia lainnya secara efektif dan efisien untuk mencapai suatu tujuan tertentu (Hasibuan, 2012:2).

\subsubsection{Manajemen Sumber Daya Manusia}

Menurut Gery Dessler (2011:31) Manajemen sumber daya manusia merupakan proses memperoleh, melatih, menilai dan memberikan kompensasi kepada karyawan, memperhatikan hubungan kerja mereka, kesehatan, keamanan dan masalah keadilan. Sedangkan MSDM menurut Malayu Hasibuan (2012:10) merupakan ilmu dan seni mengatur hubungan dan peranan tenaga kerja agar efektif dan efisien membantu terwujudnya tujuan perusahaan, karyawan dan masyarakat. 


\subsection{Disiplin kerja}

Disiplin kerja adalah suatu alat yang digunakan para manajer untuk berkomunikasi dengan karyawan agar mereka bersedia untuk mengubah suatu perilaku serta sebagai upaya untuk meningkatkan kesadaran dan kesediaan seseorang mentaati semua peraturan perusahaan dan normanorma sosial yang berlaku (Veithzal Rivai, 2011:284). Menurut Henry Simamora (2010:610) disiplin merupakan prosedur yang mengoreksi atau menghukum bawahan, karena melanggar peraturan atau prosedur kerja. Disiplin merupakan pengendalian diri karyawan dan pelaksanaan tingkat kesungguhan tim kerja di dalam suatu organisasi.

\subsection{Kompetensi}

Kompetensi menurut Darsono dan Siswandoko (2011:123) adalah perpaduan keterampilan, pengetahuan, kreativitas dan sikap positif terhadap pekerjaan tertentu yang diwujudkan dalam kinerja. Kompetensi merupakan karakter seseorang pekerja yang mampu menghasilkan kinerja terbaik di banding orang lain. Sedangkan menurut Spencer dalam Moeheriono (2012:5) merupakan karakteristik yang mendasari seseorang berkaitan dengan efektivitas kinerja individu dalam pekerjaan atau karakteristik dasar individu yang memiliki hubungan atau sebab akibat dengan kriteria menjadi acuan, efektif atau berkinerja prima atau superior ditempat kerja atau pada situasi tertentu.

\subsection{Kinerja}

Menurut Mangkunegara (2011:67) mengemukakan bahwa istilah kinerja berasal dari kata job performance atau actual performance yaitu hasil kerja secara kualitas dan kuantitas yang dicapai oleh seseorang pegawai dalam melaksanakan tugasnya sesuai dengan tanggung jawab yang diberikan kepadanya. Menurut Rivai (2011:14) kinerja merupakan hasil atau tingkat keberhasilan seseorang secara keseluruhan selama periode tertentudi dalam melaksanakan tugas, dibandingkan dengan berbagai kemungkinan seperti, standar hasil kerja, target atau sasaran serta kriteria yang telah ditentukan terlebih dahulu dan telah disepakati bersama.

\subsection{Kerangka Pemikiran}

Menurut Uma Sekaran dalam (Sugiyono, 2010:60) mengemukakan kerangka pemikiran merupakan model konseptual tentang bagaimana teori hubungan dengan berbagai factor yang telah diidentifikasikan sebagai masalah yang penting.

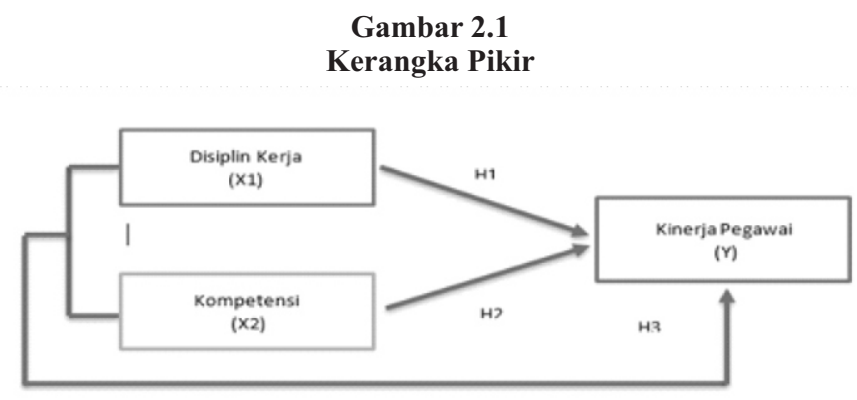

\subsection{Hipotesis}

Berdasarkan kerangka pikir di atas, maka hipotesis dari penelitian ini adalah:

H 1 : Terdapat pengaruh secara parsial variabel disiplin kerja terhadap kinerja pegawai

H2: Terdapat pengaruh secara parsial variabel kompetensi terhadap kinerja pegawa

H3: Terdapat pengaruh secara simultan variabel disiplin kerja dan kompetensi terhadap kinerja pegawai 


\section{Metodologi Penelitian}

\subsection{Metode Penelitian}

Menurut Sugiyono (2010:20) "Penelitian deskriptif yaitu metode penelitian yang digunakan untuk menganalisis suatu data statistik secara deskriptif." Sedangkan menurut Sujarweni (2014:11) "Penelitian desktiptif adalah jenis penelitian yang memberikan gambaran atau uraian atas suatu keadaan sejelas mungkin tanpa ada perlakuan terhadap objek yang diteliti." Penelitian ini bertujuan untuk pengaruh disiplin kerja dan kompetensi terhadap kinerja pada Pusat Penelitian Kebijakan Pendidikan dan Kebudayaan.

\subsection{Sumber Data}

Sumber data yang digunakan dalam penelitian ini adalah data primer dan sekunder. Untuk mendukung penelitian ini dan memperoleh data yang dibutuhkan, maka jenis data yang digunakan adalah data primer yang diambil langsung dari sumber primer. Sumber primer adalah data yang langsung memberikan data kepada sumber aslinya (Sugiyono, 2011:137). Sumber primer ini dikumpulkan melalui metode wawancara dalam penelitian ini menggunakan metode wawancara tidak terstruktur dan survey menggunakan kuesioner yang dibuat oleh peneliti. Menurut sumbernya, data sekunder adalah data yang diambil dari sumber sekunder. Sumber sekunder adalah sumber yang tidak langsung memberikan data kepada pengumpul data, misalnya lewat orang lain atau lewat dokumen (Sugiyono, 2011:137). Data sekunder dalam penelitian ini adalah studi pustaka dan dokumentasi.

\subsection{Populasi dan Sampel}

Hamidi $(2007 ; 126)$ dalam judul bukunya; Metode Penelitian dan Komunikasi, menyatakan bahwa: "populasi adalah keseluruhan satuan analisis (unit of analysis) yang hendak diteliti, dalam hal ini adalah individu-individu responden". Kemudian sesuai dengan permasalahan penelitian, Peneliti harus menetapkan kriteria populasi. Jika unit analisisnya individu, maka individu di lingkungan mana yang akan dijadikan populasinya. Dengan demikian tujuan menetapkan kriteria adalah untuk menentukan siapa yang memenuhi syarat untuk dijadikan responden dan siapa yang tidak memenuhi ketentuan persyaratan tersebut. Populasi dalam penelitian ini adalah 109 pegawai.

\subsubsection{Sampel}

Menurut Sugiyono (2009:91) dalam judul bukunya; Metode Penelitian Bisnis, menyatakan bahwa: "sampel adalah bagian dari jumlah dan karakteristik yang dimiliki oleh populasi tersebut". Bila terdapat populasi yang besar dan peneliti tidak mungkin mempelajari semua yang ada pada populasi, misalnya karena keterbatasan dana, tenaga dan waktu, maka peneliti dapat menggunakan sampel yang di ambil dari populasi itu. Menurut Sarjono dan Julianita (2011:30) "ukuran dari sampel yang akan dijadikan objek penelitian ditentukan dengan pendekatan rumus slovin dengan persentase sampling error yang ditoleransi 10\%". Rumus slovin adalah sebagai berikut:

Keterangan:

$\mathrm{n}=$ jumlah sampel

$\mathrm{N}=$ jumlah populasi

$\mathrm{e}=$ batas ketelitian yang diinginkan

$\mathrm{n}=\frac{109}{1+109(0,05)^{2}}$

$=86$

Jadi, berdasarkan perhitungan diatas, maka jumlah sampel adalah sebanyak 109. Dalam peneliti ini teknik sampel yang digunakan adalah metode sampel proportionate stratified random sampling. proportionate stratified random sampling digunakan bila populasi mempunyai unsur/anggota yang tidak homogen dan berstrata secara proporsional (Sugiyono, 2017:64). 


\subsection{Teknik Pengumpulan Data}

Sesuai dengan metode penelitian yang digunakan, yakni metode survei, maka untuk memperoleh data yang diperlukan dalam penelitian ini, pengumpulan data dilakukan dengan menggunakan metode-metode field research dan library research. Dalam kuisioner tersebut digunakan skala Liker tuntuk mengukur sikap, pendapat, dan persepsi seseorang atau sekelompok orang tentang fenomena sosial. Dengan skala Likert, maka variabel yang akan diukur dijabarkan menjadi indikator variabel. Kemudian indikator tersebut dijadikan sebagai titik tolak untuk menyusun item-item instrument yang dapat berupa pernyataan atau pertanyaan. Jawaban dari setiap item instrument yang menggunakan skala Likert mempunyai gradasi dari sangat positif sampai sangat negatif.

\subsection{Teknik Analisis Data}

Penelitian ini melihat hubungan yang terjadi independent variable dengan dependent variable melalui korelasi. Derajat atau tingkat hubungan antara dua variabel diukur dengan menggunakan indeks korelasi, yang disebut koefisien korelasi. Dalam penelitian ini digunakan teknik korelasi sederhana dan multiple-regression analysis. Koefisien-koefisien regresi distandarisasikan untuk mengurai hubungan antara dua variabel bebas dan satu variabel terikat. Dalam pengamatan dan penganalisaan serta pengukuran normalitas, setiap faktor akan dilihat hubungan melalui korelasi sederhana. Hubungan variabel bebas dan terikat secara keseluruhan akan ditinjau lebih jauh untuk mengetahui tingkatan korelasi yang multiple. Metode analisis data yang digunakan dalam penelitian ini adalah uji Deskriptif, Uji Kualitas data (Uji validitas dan Uji reliabilitas), Analisis Regresi Linear berganda yang terdiri dari Uji Asumsi Klasik (Uji Normalitas, Uji Multikolonieritas, dan Uji Heteroskedastisitas), Uji Hipotesis (Uji Signifikansi t dan Uji F), dan Uji Koefisien Determinasi.

\section{Analisis dan Pembahasan}

\subsection{Hasil Uji Deskriptif}

Menurut Jonathan Sarwono, 2016:53), Stastistik deskriptif memberikan gambaran data yang ada secara deskripsi suatu data dari nilai-nilai rata-rata (mean), standar deviasi, varian, maksimum, minimun, range, kurtosis dan skewness (kemencengan distibusi). Variabel yang digunakan dalam penelitian ini yaitu disiplin kerja, kompetensi, dan kinerja pegawai akan di uji secara deskriptif. Metode pengolahan data yang digunakan pada penelitain ini adalah metode analisis deskriptif dan metode analisis inferensial. Metode analisis deskriptif adalah statistik yang digunakan untuk menganalisa data dengan cara mendeskripsikan atau menggambarkan data yang telah terkumpul sebagaimana adanya tanpa bermaksud membuat kesimpulan yang berlaku untuk digeneralisasikan. Termasuk dalam statistik deskriptif antara lain adalah penyiapan data dalam bentuk tabel, grafik, perhitungan median, mean, standart deviasi, perhitungan prosentase, dan lain-lain (Sugiyono, 2009: 207). Adapun untuk kepentingan penelitian ini menggunakan program SPSS for window. Berdasarkan data variabel terikatnya $(\mathrm{Y})$ adalah kinerja dan variabel bebasnya adalah displin kerja $\left(\mathrm{X}_{1}\right)$, dan kompetensi $\left(\mathrm{X}_{2}\right)$.

\begin{tabular}{|c|c|c|c|c|c|}
\hline & \multicolumn{3}{|c|}{$\begin{array}{c}\text { Tabel } 4.1 \\
\text { Descriptive Statistics }\end{array}$} & \multirow[b]{2}{*}{ Mean } & \multirow[b]{2}{*}{ Std. Deviation } \\
\hline & $\mathrm{N}$ & Minimum & Maximum & & \\
\hline$\overline{\mathrm{DK}}$ & 8 & 15.00 & 25.00 & 21.4767 & 2.59740 \\
\hline K & 8 & 77.00 & 105.00 & 90.5930 & 6.96610 \\
\hline KN & 8 & 21.00 & 35.00 & 29.5814 & 3.22295 \\
\hline Valid N (listwise) & 8 & & & & \\
\hline & & & & & \\
\hline
\end{tabular}


Tabel di atas, menunjukkan bahwa pada variabel disiplin kerja memiliki jawaban minimum responden yang didapat dari penyebaran kuesioner adalah sebesar 15 dan jawaban maksimum responden yang di dapat dari penyebaran kuesioner adalah sebesar 25 , dengan rata-rata total jawaban 21,47 dan standar deviasi sebesar 2,59740. Variabel kompetensi memiliki jawaban minimum responden yang didapat dari penyebaran kuesioner adalah sebesar 77 dan jawaban maksimum responden yang didapat dari penyebaran kuesioner adalah sebesar 105, dengan rata-rata total jawaban 90,59 dan standar deviasi sebesar 6,96610.Sedangkan variabel Kinerja memiliki jawaban minimum responden yang didapat dari penyebaran kuesioner adalah sebesar 21 dan jawaban maksimum responden yang didapat dari penyebaran kuesioner adalah sebesar 35, dengan rata-rata total jawaban sebesar 29,58dan standar deviasi sebesar 3,22295.

\subsection{Hasil Uji Hipotesis}

\section{Uji parsial t}

Uji t digunakan Uji t dilakukan dengan cara membandingkan perbedaan antara nilai dua nilai ratarata dengan standar error dari perbedaan rat-rata dua sampel (Ghozali,2013:98). Untuk menguji pengaruh masing-masing variabel bebas yang digunakan dalam penelitian ini secara parsial digunakan uji t dengan signifikansi 5\% (Ghozali,2013). Jika nilai signifikansi lebih kecil dari 0,05 atau $\mathrm{t}_{\text {hitung }}$ lebih besar $\mathrm{t}_{\text {tabel }}$ maka $\mathrm{H}_{\mathrm{a}}$ diterimadan $\mathrm{H}_{\mathrm{o}}$ ditolak, sedangkan jika nilai signifikansi lebih besar dari 0,05 atau $\mathrm{t}_{\text {hitung }}$ lebih kecil dari $\mathrm{t}_{\text {tabel }}$ maka $\mathrm{H}_{\mathrm{o}}$ diterima dan $\mathrm{H}_{\mathrm{a}}$ ditolak (Sujarweni dan Endaryanto,2012:137). Ttabel $: \mathrm{t}(\mathrm{a} / 2: \mathrm{n}-\mathrm{k}-1)=\mathrm{t}(0,05 / 2: 86-2-1)=1,992$.

\begin{tabular}{|c|c|c|c|c|c|c|}
\hline \multirow[b]{3}{*}{ Model } & \multicolumn{6}{|c|}{$\begin{array}{c}\text { Tabel } 4.1 \\
\text { Uji t } \\
\text { Coefficients }^{\mathrm{a}}\end{array}$} \\
\hline & & \multicolumn{2}{|c|}{ Unstandardized Coefficients } & \multirow{2}{*}{$\begin{array}{l}\text { Standardized } \\
\text { Coefficients } \\
\text { Beta }\end{array}$} & \multirow[b]{2}{*}{$\mathrm{t}$} & \multirow[b]{2}{*}{ Sig. } \\
\hline & & B & Std. Error & & & \\
\hline 1 & (Constant) & -1.405 & 2.895 & & -.485 & .629 \\
\hline & Disiplin_Kerja & .618 & .094 & .498 & 6.545 & .000 \\
\hline & Kompetensi & .195 & .035 & .422 & 5.546 & .000 \\
\hline
\end{tabular}

Hasil uji statistik dapat dilihat pada tabel berikut:

a. Pengaruh disiplin kerja terhadap kinerja pegawai

Berdasarkan hasil output pada tabel variabel disiplin kerja diperoleh nilai thitung sebesar 6,545> $\mathrm{t}$ tabel 1,992 dan nilai signifikansi $0,000<0,05$. Maka dapat dikatakan bahwa disiplin kerja berpengaruh positif secara signifikan terhadap kinerja pegawai pada Pusat Penelitian Kebijakan Pendidikan dan Kebudayaan (Puslitjakdikbud) karena tingkat signifikansi yang dimiliki variabel disiplin kerja lebih kecil dari 0,05 yang berarti disiplin kerja memiliki pengaruh yang signifikan bagi kinerja pegawai yang bekerja di Pusat Penelitian Kebijakan Pendidikan dan Kebudayaan (Puslitjakdikbud).

b. Pengaruh kompetensi terhadap kinerja pegawai

Berdasarkan hasil output, pada variabel kompetensi diperoleh nilai t hitung sebesar 5,546 >t tabel 1,992 dan nilai signifikansi (sig) $0,000<0,05$. Maka dapat diartikan bahwa $\mathrm{H}_{0}$ ditolak dan $\mathrm{H}_{\mathrm{a}}$ diterima. Sehingga dapat dikatakan bahwa kompetensi berpengaruh secara signifikan terhadap kinerja pegawai Pusat Penelitian Kebijakan Pendidikan dan Kebudayaan karena tingkat signifikansi yang dimiliki variabel kompetensi lebih kecil dari 0,05 yang berarti kompetensi memiliki pengaruh yang signifikan bagi kinerja pegawai yang bekerja di Pusat Penelitian Kebijakan Pendidikan dan Kebudayaan(Puslitjakdikbud). 


\section{2. $\mathrm{Uji} F($ Simultan)}

Pengujian secara simultan dilakukan dengan menggunakan uji $\mathrm{F}$ dilakukan untuk mengetahui apakah semua variabel independen dalam model mempunyai pengaruh variabel dependen yang diuji secara simultan. Apabila nilai signifikansi $<0,05$ atau $\mathrm{f}$ hitung $>\mathrm{f}$ tabel maka $\mathrm{H}_{\mathrm{a}}$ diterima $\mathrm{H}_{\mathrm{o}}$ ditolak. Demikian pula sebaliknya jika sig $\mathrm{t}>0,05$ atau $\mathrm{f}$ hitung, maka $\mathrm{H}_{\mathrm{o}}$ diterima dan $\mathrm{H}_{\mathrm{a}}$ ditolak. (Ghozali,2013:98).

$\mathrm{F}$ tabel $=\mathrm{F}(\mathrm{k}: \mathrm{n}-\mathrm{k})=\mathrm{F}(2: 86-2)=\mathrm{F}(2: 84)=3,11$

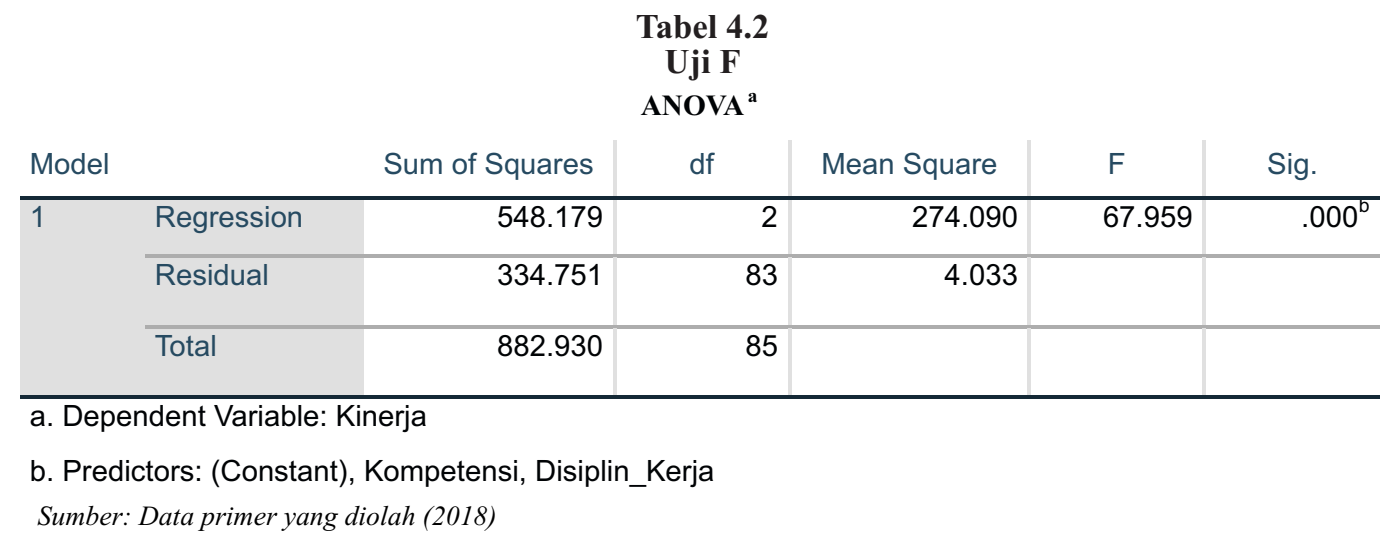

Hasil uji $\mathrm{F}$ dapat di lihat pada tabel di atas, nilai $\mathrm{F}$ diperoleh sebesar 67,959 dengan signifikansi 0,000. Ini berarti model regresi ini layak diuntuk digunakan karena nilai signifikansi kurang dari 0,05 dan F hitung lebih besar dari F tabel. Sehingga dapat dikatakan bahwa variabel disiplin kerja dan kompetensi secara simultan berpengaruh secara signifikan terhadap variabel kinerja pegawai.

\subsection{Uji Koefisien Determinasi}

Koefisien Determinasi $\left(\mathrm{R}^{2}\right)$ pada intinya mengukur seberapa jauh kemampuan model dalam menerangkan variasi variabel independent. Niali $R^{2}$ yang kecil berarti kemampuan variabel independent dalam menjelaskan variabel dependen sangat terbatas. Nilai yang mendekati satu berarti variabel-variabel independent memberikan hampir semua informasi yang dibutuhkan untuk memprediksi variabel dependen (Ghozali, 2013:93).

Tabel 4.3

Uji Koefisien Determinasi $\left(\mathbf{R}^{2}\right)$

\section{Model Summary}

\begin{tabular}{|c|c|c|c|c|}
\hline Model & $\mathrm{R}$ & R Square & Adjusted R Square & $\begin{array}{l}\text { Std. Error of the } \\
\text { Estimate }\end{array}$ \\
\hline 1 & $.788^{\mathrm{a}}$ & .621 & .612 & 2.00827 \\
\hline
\end{tabular}

Berdasarkan tabel 4.3 hasil model summary di atas penelitian ini nilai Adjusted R Square sebesar 0,612 atau $61,2 \%$ ini menunjukkan bahwa variabel yang dapat dijelaskan oleh variabel disiplin kerja dan kompetensi adalah sebesar $61,2 \%$. Sedangkan sisanya sebesar 0,338 atau 33,8\% dipengaruhi variabel lain yang tidak diteliti dalam penelitian ini. 


\section{Simpulan dan Saran}

\subsection{Simpulan}

Penelitian ini bertujuan untuk mengetahui pengaruh dari disiplin kerja dan kompetensi terhadap kinerja pegawai di Pusat Penelitian Kebijakan Pendidikan dan Kebudayaan. Berdasarkan dari hasil analisis dan pembahasan yang dilakukan dengan menggunakan regresi linear berganda, dapat ditarik kesimpulan sebagai berikut:

1. Disiplin kerja mempunyai pengaruh yang signifikan terhadap kinerja pegawai di Pusat Penelitian Kebijakan Pendidikan dan Kebudayaan

2. Kompetensi mempunyai pengaruh yang signifikan terhadap kinerja pegwai di Pusat Penelitian Kebijakan Pendidikan dan Kebudayaan

3. Disiplin kerja dan Kompetensi secara bersama-sama atau simultan mempunyai pengaruh yang signifikan terhadap kinerja pegawai di Pusat Penelitian Kebijakan Pendidikan dan Kebudayaan

\subsection{Saran}

1. Bagi Akademisi

Bagi kalangan akademisi, diharapkan penelitian selanjutnya dapat menggunakan penelitan ini sebagai refrensi untuk penelitan-penelitan selanjutnya yang memiliki tema yang sama yaitu pengaruh disiplin kerja dan kompetensi terhadap kinerja pegawai. penelitian selanjutnya disarankan untuk mengkaji komponen lain selain masalah disiplin kerja, kompetensi dan kinerja pegawai yang telah dibahas oleh penulis atau dengan dimensi dan indikator-indikator yang berbeda serta didukung oleh teori-teori atau penelitian terdahulu.

2. Bagi Puslitjakdikbud

a. Pada variabel disiplin kerja bahwa Pusat Penelitian Kebijakan Pendidikan dan Kebudayaan diharapkan dapat memperhatikan tingkat kehadiran pegawai, karena mengingat disiplin kerja amatlah penting untuk menunjang kemajuan instansi. Pihak instansi harus memberikan sanksi yang tegas untuk para pegawai yang kurang disiplin terhadap jam kerja berupa pemotongan uang remunerasi.

b. Pada variabel kompetensi bahwaPusat Penelitian Kebijakan Pendidikan dan Kebudayaan harus memperhatikan keahlian dan keterampilan yang dimiliki pegawai, dan menyesuaikannya dengan job description untuk masing-masing pegawai dengan memberikan penjelasan tentang apa yang harus dilakukan untuk meningkatkan kompetensi. Hal ini dapat dilakukan dengan mengadakan pendidikan nonformal untuk pegawai seperti pelatihan-pelatihan yang terkait dengan pekerjaannya dan menempatkan pegawai sesuai dengan kemampuan dan keahliannya.

\section{Daftar Pustaka}

Dessler, Gary. 2009. Human Resource Management. Prentice-Hall, Inc. New Jersey,

Handoko, T. Hani. 2008. Manajemen Personalia Sumber Daya Manusia". Edisi Kedua. BPFE. Yogyakarta:

Hasibuan, Malayu S.P. 2012. Manajemen Sumber Daya Manusia. PT. Bumi Aksara. Jakarta.

Helmi. 2012. Pengembangan Sumber Daya PNS". Jurnal Administrasi Publik, Vol 10, No 2, Desember,

Istiqomah Siti. "Pengaruh Disiplin Kerja dan Iklim Organisasi Terhadap Kinerja Pegawai Dinas Perhubungan Kota Yogyakarta Dengan Motivasi Kerja Sebagai Variabel Intervening”. Jurnal Siasat Bisnis, Vol 19, No 1, Januari, 2015. h.89-97.

Jeffrey, Ignatius. "The Effect Of Competence, Training, and Work Discipline towrads Employees' Performance". International Journal Of Business Management Invention, Volume 6, Nomor 7, Juli, 2017. 
Lufti, Wildan. "Implementasi dan Peraturan Pemerintah Nomor 53 Tahun 2010 Tentang Disiplin Pegawai Khususnya Aspek Jam Kerja Pada Kabupaten Kutai Kartanegara". Jurnal Borneo Administrator, Volume 11, No 3, Desember 2015.

Mangkunegara. "Manajemen Sumber Daya Manusia". Bandung: PT. Remaja Rosdakarya, 2011.

Moeheriono. "Pengukuran Kinerja Berbasis Kompetensi". Jakarta ; Raja Grafindo Persada, 2012.

Putra, Aldo. "Pengaruh Disiplin Kerja Terhadap Kinerja Pegawai Pada Badan Perpustakaan dan Arsip Daerah Provinsi Kepulauan Riau". Jurnal Ilmiah Prodi Ilmu Administrasi Negara Fisip Universitas Riau, Volume 3, Nomor 1, Oktober 2013.

Samsudin, Sadili. "Manajemen Sumber Daya Manusia". Bandungg: CV Pustaka Setia, 2010.

Simamora, Henry. “Manajemen Sumber Daya Manusia”. Yogyakarta : STIE YKPN, 2011.

Siswandoko dan Darosno. "Sumber Daya Manusia Abad 21". Jakarta : Nusantara Consulting, 2011.

Sudarweti, Suparno. "Pengaruh Motivasi, Disiplin Kerja, dan Kompetensi Terhadap Kinerja Pegawai Dinas Pendidikan Kabupaten Sragen”. Jurnal Paradigma, Vol 12, No 1, Juli, 2014.

Sugiyono. "Metode Penelitian Kuantitatif, Kualitatif dan R\&D”. Bandung : Alfabeta, 2013.

Sugiyono. "Statistika UntukPenelitian". Edisi ke 28. Bandung :Alfabeta, 2017. 